\title{
Measuring Social Solidarity. Some Research Notes
}

\author{
Horațiu Rusu ${ }^{*}$
}

${ }^{1}$ Lucian Blaga University of Sibiu, Department of Sociology and Social Work, 2-4 Lucian Blaga, 550169 Sibiu, Romania

KEYWORDS

Social solidarity Construct validation Confirmatory factor analysis

\begin{abstract}
There is an increasing public, political and research interest in social solidarity. Even though the concept has a long history and is embedded in solid approaches, there is not much literature concerned with its measurement. The paper falls into the area of the methodological studies of social solidarity and it deals with construct validation. The objective of this paper is to test for convergent validity and nomological validity of two sets of items aiming to measure social solidarity attitudes and acts. The main method employed is confirmatory factor analysis.
\end{abstract}

\section{Introduction}

Early sociologists defined social solidarity and cohesion as the cement of societies, the fabric that ties people together (Durkheim 1964 [1895]; Tönnies 1957 [1887]). Having a long history, its study entered repeatedly in shaded areas and, only in the last decade, after a long period of decay from the sociologists' agenda, its career flourishes again (Stjernø 2004: 288). Even though an increasing amount of recent literature is questioning the status of social solidarity across Europe (e.g. Stjernø 2004; Michalski 2006; de Beer \& Koster 2009; Ellison 2011) not many empirical analyses, especially ones engaging quantitative methodologies, are available and, even fewer methodological studies exist. This paper presents some research notes that could contribute to the work in the area of methodological studies of social solidarity. It deals with construct validation. It means that it focuses 'on the extent to which a measure performs in accordance with theoretical

\footnotetext{
* Contact address: horatiu.rusu@ulbsibiu.ro (H. Rusu).
} 
expectations' (Carmines and Zeller 1979: 27). Several steps, implied by construct validation, are taken in this paper:

'First, the theoretical relationship between the concepts themselves must be specified. Second, the empirical relationship between the measures of the concepts must be examined. Finally, the empirical evidence must be interpreted in terms of how it clarifies the construct validity of the particular measure.' (Carmines and Zeller 1979: 23).

Construct validity also implies four components: convergent validity, discriminant validity, nomological and face validity (Hair et al. 2009). The main objective of this paper is to test for convergent validity (factor loadings and reliability) and nomological validity (Hair et al. 2009) of two sets of items aiming to measure social solidarity (attitudes and acts).

The paper begins with a short review of the literature and of several empirical subjective measures of social solidarity. It is followed by a second section where brief arguments for a set of measurements of solidarity acts are introduced. The third section is dedicated to data and methodology. The fourth part presents first a confirmatory factor analysis based on items measuring solidarity attitudes, to be found in European Values Study ${ }^{1}$ and also included in an original study. Then I focus on the results of the confirmatory factor analyses of the items aiming to measure social solidarity acts and on the validation of this new scale. In the final part I draw the conclusions of the analysis.

\section{Social solidarity: a brief literature introduction and about subjective measurements.}

Social solidarity is a fuzzy concept and there is much variation in its contextualization and understanding. Broadly speaking, solidarity is both a societal characteristic (Durkheim 1964) and an individual quality (de Beer and Koster 2009: 16). Solidarity at individual level is of interest in this paper and there are, of course, different ways to understand it. For example it is

\footnotetext{
1 EVS (2011): European Values Study Longitudinal Data File 1981-2008 (EVS 1981-2008). GESIS Data Archive, Cologne. ZA4804 Data file Version 2.0.0, doi:10.4232/1.11005
} 
defined as bonding or bridging relationship between different people (Abela 2004: 73; de Beer and Koster 2009: 15), or as feelings of sympathy for and commitment to other people (Janmaat and Brown 2009), or as an empathic response to a condition distressing 'others' independently of their personal or social character (Arnsperger and Varoufakis 2003). The vast array of conceptualizations is also due to the fact that current approaches advance a variety of types of solidarity: local, social and global solidarity (Abela 2004; Kankaraš and Moors 2009); sub-national, national, transnational or international solidarity (Radtke 2007); civic solidarity (Habermas 1992, 1997); ethnic and national solidarity (Calhoun 2007); negative solidarity (Komter 2005); radical solidarity (Arnsperger and Varoufakis 2003), etc. Stjernø (2004) offers an excellent description of the classical and modern conceptualizations, functions and foundations of solidarity. Rather than focusing on these, in the followings, I revisit first few subjective measurement models of solidarity used in the literature. Second I will point out some of the concepts literature connects it with; this is of relevance one of the aims this paper being the external validation of the solidarity measurements.

Several papers (Arts and Gellissen 2001; Abela 2004; Kankaraš and Moors 2009; Janmaat and Brown 2009; de Beer and Koster 2009) make use of empirical subjective measures of social solidarity. Most of the items used in these papers are to be found in large scale comparative surveys, particularly the European Value Study.

Arts and Gellissen (2001) propose a scale that measure people's preferred level of solidarity. They are using a set of seven items from ISSP $1996^{2}$ that explore the issue of entitlement to social protection from the government. The respondents are how much it should or should not be the government's responsibility to 3 : provide a job for everybody who wants one (v36); provide health care for the sick (v38); provide a decent standard of living for the old (v39); provide a decent standard of living for the unemployed (v41); provide decent housing for those who can't afford it (v44); give financial help to college students from low-income families (v43);

\footnotetext{
2 International Social Survey Program: Role of Government III (data file: ZA2900).

3 The variable codes in parantheses are those provided in ZA2900.
} 
reduce income differences between the rich and the poor (v42). The answers are coded on a four-point scale ranging from 1 (definitely should be) to 4 (definitely should not be). By means of confirmatory factor analysis they found evidence these items load on a single dimension.

Another measurement model of socio-economic solidarity is proposed by Abela (2004). It is constructed on ten items to be found in EVS 1999/20004 that indicate the concern for the living conditions of other categories of people: immediate family (e153), people in neighbourhood (e154), people in own region (e155), fellow countrymen (e156), elderly people (e159), sick and disabled (e162), unemployed (e160), immigrants (e161), Europeans (e157), humankind (e158). The answers are coded on a five-point scale ranging from 1 (very much) to 5 (not at all). Performing exploratory factor analysis on these items, Abela (2004) found evidence for three components of socioeconomic solidarity. These three factors are named: local solidarity (e153e156), social solidarity (e159, e160, e126) and global solidarity (e157, e158, e161). This three-dimension model is tested for measurement-equivalence, using a multiple group latent class factor analysis, on the same 1999/2000 wave of EVS, by Kankaraš and Moors (2009). They find evidence of measurement equivalence of the model among countries included in EVS 1999/2009, under some conditions (e.g. when excluding Turkey from the sample and considering a partial homogenous model with 2 direct effects), thus comparisons between countries being possible.

A different measurement model of social solidarity is proposed by Janmaat and Brown (2009). They also select five items (e156, e146, e147, e038, e1905) from EVS 1999/2000. Nevertheless only one of these five items is among those used by Abela (2004): the concern for fellow countrymen (e156). Two other items ${ }^{6}$ measure the importance of what a society should provide in order to be considered just: eliminating big inequalities in income among citizens (e146); guaranteeing that basic needs are met for all, in terms of food, housing, clothing, education, health (e147). All these three items are

\footnotetext{
4 Variables codes in ZA4808 range from e153-e162.

5 Variables codes in ZA4808.

${ }^{6}$ These two items are actually used by Arts and Gellissen (2001) to assess people's choice of equality and need principles of justice.
} 
measured on a five point scale. The fourth item, measured on a ten-point scale, taps attitudes on unemployment (e038). The fifth item gauges opinions on four possible reasons why people live in need: unlack; laziness and lack of willpower; injustice in society; inevitable part of modern progress (e190). The response scale of this item was transformed in a dichotomous one. Employing a principal component analysis Janmaat and Brown (2009) conclude that the first three items (e156, e146, e147) load on a dimension they label support for general solidarity principles and the last two (e038, e190) on a dimension named compassion for the unfortunate.

De Beer and Koster (2009) construct three separate subjective measures of solidarity using items found in EVS 1999/2000. The first one captures what they call 'voluntary informal (one-sided) solidarity', that is solidarity in the form of unpaid, voluntary work. It is measured by asking respondents if they take part in voluntary activities ${ }^{7}$. More specifically, the respondents are asked: 'Which, if any, of the following voluntary organizations are you currently doing unpaid voluntary work for?'. The scale is recoded based on the number of organizations ${ }^{8}$ for which the response is positive. It varies from 1 to 15 (de Beer and Koster 2009: 85). The second measurement scale captures the willingness to help others. It is constructed as an additive index of four items to be found in EVS 1999/2000 that indicate the preparedness to actually do something to improve the conditions of the living conditions of other categories of people: immigrants; sick and disabled people; people in neighbourhood/community; elderly people. The index scale varies from 0 to 10 . The third measurement captures the preference for state-organized solidarity. It is constructed combining the index previously described with the answers, measured on a 10-point scale, to the following question ${ }^{10}$ : 'How would you place your views on this scale?: (1) Individuals should take more responsibility for providing for themselves (10) The state should take more responsibility to ensure that everyone is provided for.' The result is recoded

\footnotetext{
7 It can also be measured by means of diaries (time use surveys), where respondents record their daily activities.

8 Variables codes in ZA4808 range from a081 to a096.

${ }^{9}$ Variables codes in ZA4808 range from e164 to e167.

${ }^{10}$ Variables code in ZA4808 is e037.
} 
so to measure the lack of solidarity, voluntary solidarity and compulsory solidarity (de Beer and Koster 2009: 85).

Radtke (2007) measures solidarity in terms of declared behaviour of private donors. The questions she used from two longitudinal surveys in Germany and Switzerland capture, without making a clear-cut difference, individual donations in terms of money or in-kind donations. The response categories indicate beneficiaries of donation ranging from categories of people (e.g. children/youth; disabled and infirm; elderly) to categories of problems (e.g. poverty; environmental protection; disease control) or institutions (e.g. aid funds).

There are also measures of solidarity at individual level that can be objectively determined (e.g. private social expenditures like occupational pensions, childcare support, employment-related health plans or private insurances but they are beyond the interest of this paper (see de Beer and Koster 2009).

Among the concepts empirically linked at individual level with solidarity, we find religiosity (Abela 2004), postmaterialist value orientations (Janmaat and Brown 2009) or individualization (Abela 2004; de Beer and Koster 2009). Control variables like age, education, and income are also predictors for solidarity (Arts and Gellisen 2001; Janmaat and Brown 2009; de Beer and Koster 2009).

Abela (2004) found several significant connections between religiosity and solidarity. He identified a significant relation between three types of solidarity (local, social and global) and individualized religion (measured as the importance of God in life). Institutionalized religion (measured in terms of belonging to a religious denomination) it is not connected with local and global solidarity but significantly related with social solidarity.

Janmaat and Brown (2009) found significant links between postmaterialism and two measures of solidarity ('support for general solidarity principles' and 'compassion for unfortunates') but acting inconsistent (between the two measures in what concerns Eastern Europe) and in diverging directions in Western Europe and Eastern Europe (in what concerns the first measure 'support for general solidarity principles'). Individualization is seen by de Beer and Koster (2009) as detraditionalization, emancipation and heterogenization. They measure 
detraditionalization by means of loosening of ties between individuals and traditional institutions (i.e. traditional family and membership status in religious organizations, labour union, professional and political organizations) and find a significant negative relation with one-sided solidarity. Abela (2004) measures individualisation directly, by means of a scale ${ }^{11}$, to be found in European Values Survey 1999 and 2008. The scale is drawn on the original Rokeach (1973) instrumental values scale. Abela (2004) found significant, but inconsistent (diverging), links between individualism and two types of solidarity (local vs. global) and a non significant relation between individualism and social solidarity.

Some of these relations will be tested in the last part of the paper, where external validation of a scale is pursued.

\section{Arguments for a set of items aiming to measure social solidarity acts}

The set of items aiming to measure solidarity behaviours considers the distinction de Beer and Koster (2009: 18) speak about, between attitudes and acts of solidarity: 'The term solidarity is associated both with feelings and attitudes and with action. An act of solidarity makes a solidaristic attitude tangible in a sense'. However, as de Beer and Koster (2009) note they do not need to be directly related.

Time, money and in-kind 'investments' are forms of solidarity acts (de Beer and Koster 2009: 22). Giving alms to a beggar or donating money for the victims of an earthquake are such examples of solidarity acts (de Beer and Koster 2009: 20)

The scale that is introduced here aims to measure social solidarity by means of declared acts of giving money or in-kind benefits toward categories of persons perceived as being in distressed conditions. A similar question is used when analysing solidarity by Radtke (2007).

\footnotetext{
${ }^{11}$ In other studies this scale is used to measure autonomy versus authority/ conformity (e.g. Inglehart 1997; Hagenaars, Halman and Moors 2003; Rusu 2008; Tufiș 2008)
} 


\section{Data and methods}

An original set of data is mainly used in this paper. Data come from an original study ${ }^{12}$, a convenience sample of 200 observations. I also use, for illustrative purposes only, the Romanian dataset of the EVS 1999 and 2008.

The scope of the paper is construct validity, which is empirically validation of two sets of items that theoretically measure social solidarity. The specific objectives of this analysis are: a) to test, first, the convergent validity in terms of factor loadings and internal consistency (reliability) of the scale of social solidarity attitudes (variables codes in ZA4808 range from e153-e162) proposed by Abela (2004) on the data provided by the original study and at the same time to test its convergent validity on the Romanian dataset for the European Values Study from 1999 and 2008; and, b) to check the convergent validity and nomological validity of the items (and scale) aiming to measure solidarity behaviours on the data provided by the original study.

Convergent validity is tested by means of factor loadings and reliability as suggested by (Hair et al. 2009). Internal consistency (reliability analysis) refers to the correlations between the items of the same scale. Theoretically it is a check of the interchangeability property. This means that an item of the scale measure the exact same theoretical construct as the other items. The method employed is confirmatory factor analysis.

Nomological validity implies testing correlations among constructs (Hair et al. 2009). The external validation of a construct implies:

'that the relationship among multiple indicators designed to represent a given theoretical concept and theoretically relevant external variables should be similar in terms of direction, strength, and consistency.' (Carmines and Zeller 1979: 26).

This means on one hand that the underlying factor(s) of the proposed items correlate(s) with the underlying factor(s) of the attitude scale of social solidarity and, on the other hand, it means that both scales of social solidarity (measuring attitudes and acts/behaviours) should correlate the same way with one or few external relevant variables suggested by theory.

12 For a brief description of the sample caracteristics see Voicu (2012: 54), this issue. 
Since our original data set does not include a part of the variables specified above (post-materialism, religiosity, etc.), I will correlate the solidarity measures with individualisation and controls like age, education, household, income. Even though the measurement of the latter is inspired by the measurement used by Abela (2004), the index I use is constructed in a slightly different way (see Hagenaars, Halman and Moors 2003). It is an index of an additive type ${ }^{13}$ : the items ${ }^{14}$ that refer to the support for autonomy, namely independence (a029), responsibility feeling (a032), imagination (a034) and perseverance/determination (a039) are summed up, and the ones that refer to the support for authority, namely hard work (a030), thrift (a038), religious faith (a040), obedience (a042) were subtracted. The index response scale ranges from 1 to 9 , higher values indicating higher support for individualisation. Education is measured in terms of a variable indicating the number of years of education: the age when completing full time education. Income is measured as the net income of the household in a regular month declared by the respondent.

Individualisation, as suggested by the literature (Abela 2004; de Beer and Koster 2009) should be negatively related with solidarity. Nevertheless it is more important, for the scope of this paper, to find a consistent relation between the different types of solidarity and individualism, than to confirm a specific type (negative) of relation. Since the literature points out different links between control variables (age, education, income) and various types of solidarity (Abela 2004; Jaanmat and Brown 2009; de Beer and Koster 2009) and because the character of the sample, I do not hypothesize a specific type of relation (negative or positive) but, again, I am interested in checking if the same relation holds across all measurements of solidarity.

\footnotetext{
13 The individuals in the sample group were asked to specify 'which are the most important things children could learn at home'. A maximum of five choices were allowed, from a list including ten variables.

${ }^{14}$ The variable codes in parantheses are those provided in ZA4808.
} 


\section{Analysis}

\subsection{Testing the convergent validity of the scale of attitudes of social solidarity ${ }^{15}$}

The analysis is performed on original data and for illustrative purposes results of analysis on EVS 1999 and EVS 2008 are also shown. Before any test concerning the internal consistency of the scale is made, a check of the missing responses and a normality check are performed. All variable have missing observations but the maximum number is 4 (e161), thus not raising any special problems. All variables (except e155 and e156) are slightly asymptotic but do not raise important normality problems (both skewness and kurtosis values are acceptable).

In order to test the internal consistency of the social solidarity attitudes scale I performed first a confirmatory factor analysis (MLE method ${ }^{16}$ ) using Mplus7 (Muthen and Muthen 1998-2012) of the model proposed by Abela (2004) and tested by Kankaraš and Moors (2009). The three latent variables are clearly discriminated (Table 1, Model 1 and Figure 1) and the fit indices are acceptable ${ }^{17}$ (see Table 1).

Table 1.

\begin{tabular}{|l|c|c|}
\hline & $\begin{array}{c}\text { Model 1 } \\
\text { (see Figure 1) }\end{array}$ & $\begin{array}{c}\text { Model 2 } \\
\text { (see Figure 2) }\end{array}$ \\
\hline Fit indices & \multicolumn{2}{|l|}{} \\
\hline Chi-Square Test of Model Fit Value/df & 2.615 & 2.640 \\
\hline Value & 83.684 & 63.364 \\
\hline df & 32 & 24 \\
\hline P-value & 0.000 & 0.000 \\
\hline CFI & 0.951 & 0.962 \\
\hline TLI & 0.931 & 0.943 \\
\hline AIC & 5256.440 & 4631.472 \\
\hline BIC & 5365.284 & 4730.271 \\
\hline Sample-Size Adjusted BIC & 5260.737 & 4635.230 \\
\hline RMSEA & 0.090 & 0.091 \\
\hline SRMR & 0.051 & 0.047 \\
\hline
\end{tabular}

\footnotetext{
${ }^{15}$ For an ease of understanding I will use the same variables codes as in ZA4808.

${ }^{16}$ The same estimator is used for all models with continuos outcomes in this paper.

17 In well fitting models the values of these indices are: RMSEA $\leq 0.06, \mathrm{SRMR} \leq 0.08, \mathrm{CFI} \geq 0.95$, TLI $\geq 0.95$ (Hu and Bentler 1999); although various cut-off points are suggested by different authors (see Brown 2006; Chen et al 2008; Hair et al. 2009; Byrne 2010; Muthen 1998-2004).
} 
The fit indices are affected by the sample size, they tend to have higher values when larger samples are used (see Hu and Bentler 1999; Chen et al. 2008) thus the values obtained for RMSEA and SRMR cloud be due to the rather small sample size. However the standardized loading18 (see Figure 1) of one item (e153) is below 0.5 (Hair et al. 2009) or even 0.4 (Brown 2006: 130). A similar situation results when performing the analysis on the Romanian sample of EVS1999 (results are presented in Table 2, Model 3 and Figure 3) and EVS2008 (results are presented in Table 2, Model 4 and Figure 4). In both cases (the analysis performed on EVS 1999 and EVS 2008) the fit indices (Chi-Square Test of Model Fit Value/df, CFI, TLI, RMSEA) point out that the model should be rejected (see Table 2).

Table 2.

\begin{tabular}{|l|c|c|}
\hline & $\begin{array}{c}\text { Model 3 } \\
\text { (see Figure 3) }\end{array}$ & $\begin{array}{c}\text { Model 4 } \\
\text { (see Figure 4) }\end{array}$ \\
\hline Fit indices & \multicolumn{2}{|c|}{} \\
\hline Chi-Square Test of Model Fit Value/df & 12.60 & 25.75 \\
\hline Chi-Square Value & 403.469 & 824.001 \\
\hline $\mathrm{df}$ & 32 & 32 \\
\hline P-value & 0.000 & 0.000 \\
\hline CFI & 0.947 & 0.915 \\
\hline TLI & 0.926 & 0.880 \\
\hline RMSEA & 0.101 & 0.129 \\
\hline SRMR & 0.053 & 0.074 \\
\hline
\end{tabular}

Some of the indices seem to look a bit better (CFI - increases, AIC and BIC - decrease), when 'e153' is removed ${ }^{19}$ from the analysis (Table 1, Model 2 and Figure 2). Still, for the same reason as mentioned above, not all the fit indices are good (RMSEA). Nevertheless, there are not only statistical arguments to exclude the item from the model but also theoretical ones. Following Arnsperger and Varoufakis (2003: 161) solidarity requires 'a generosity of spirit that extends to larger numbers'. This means targets are categories or class of persons rather than specific persons (see also de Beer and Koster 2009). Therefore, to it seems preferable to build a measurement

\footnotetext{
${ }_{18}$ All the loadings presented in the paper are standardized loadings.

19 The number of cases drops to 199 because there is one observation with missing on all variables.
} 
model of solidarity attitudes that excludes the concern for immediate family (item e153).

Figure 1.

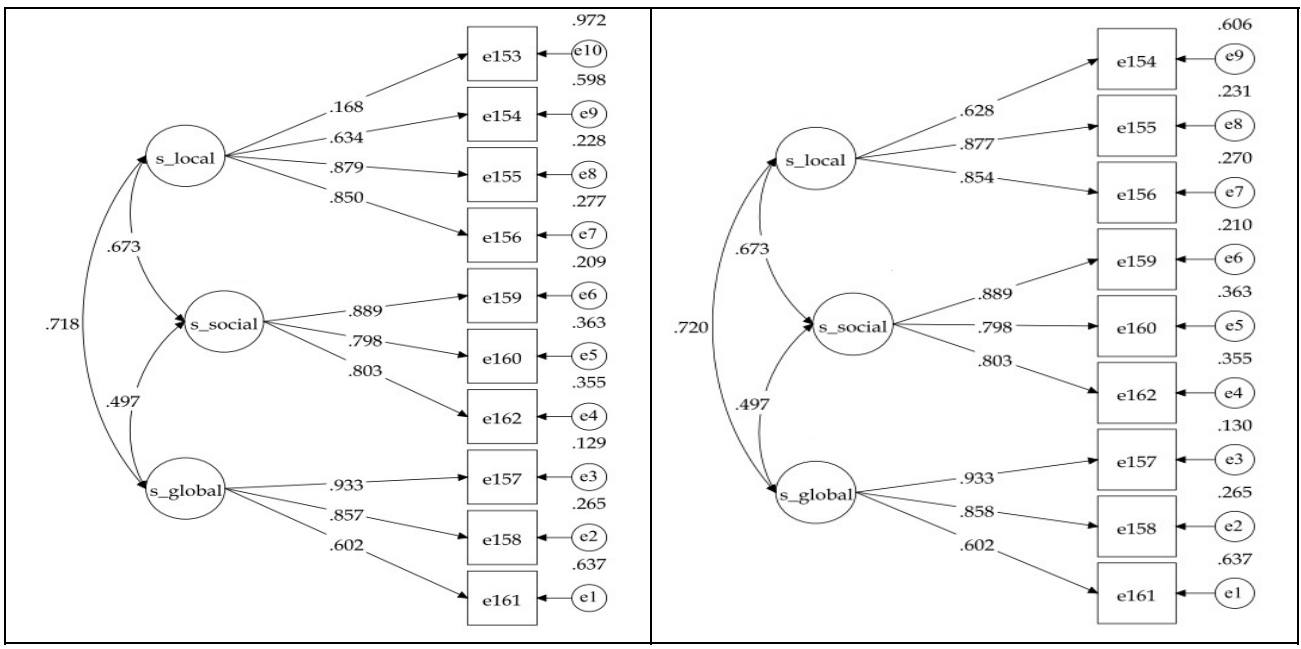

Figure 3.

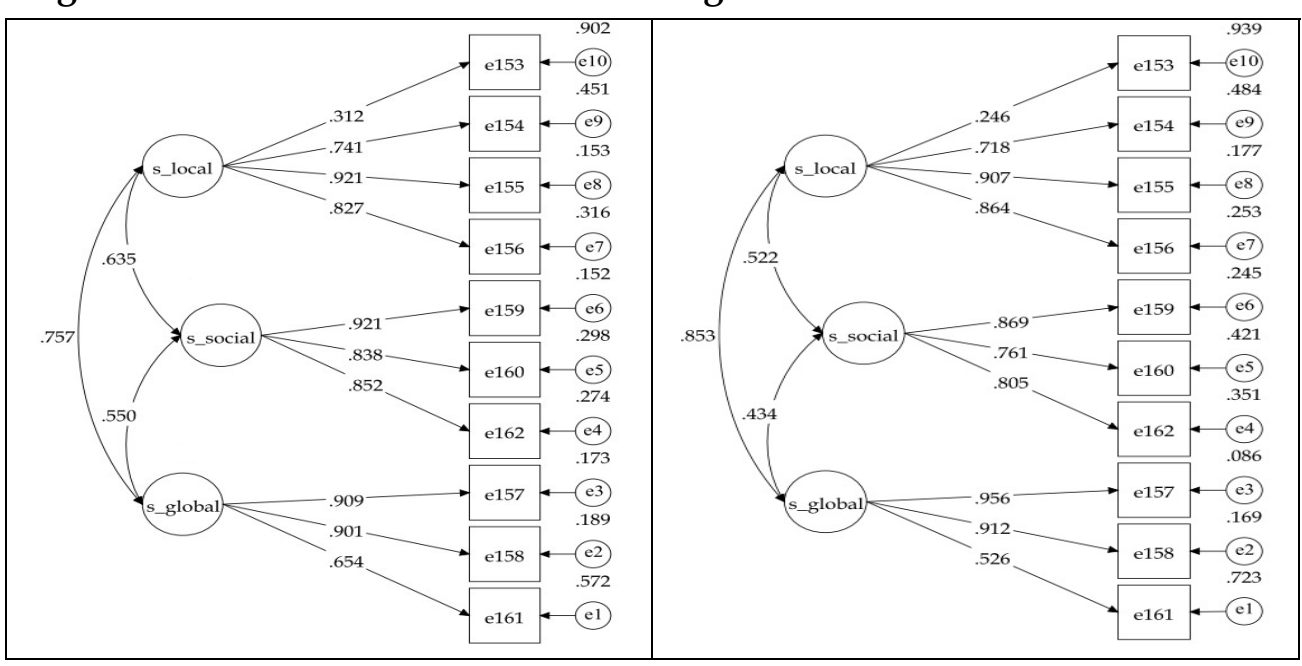

Figure 4. 


\subsection{Testing the validity of the scale of acts of solidarity}

The items used by Abela (2004) and Kankaraš and Moors (2009) and tested above, target solidarity attitudes. The set of items introduced below aims to measure acts of social solidarity by means of donations. The items do not make a clear cut between financial and in-kid donations. The respondents were asked if they donated ${ }^{20}$, in the last two years, money, food or goods to several categories or people or institutions: people in need $(x 41)$, people affected by natural disasters $(x 42)$, sick people $(x 43)$, neighbours $(x 44)$, beggars $(x 45)^{21}$, church $(x 46)$, charities $(x 47)$. The answers are coded on an ordinal categorical scale: never (coded 1), once (coded 2) and a few times (coded 3). There are two kinds of expectations one may have from these items: either they all load on one encompassing factor, or, they load on two factors, one expressing solidarity with other categories of people and one expressing solidarity acts directed towards institutions that are perceived as mediating solidarity relations.

Again, before any test concerning the internal consistency of the scale is made, a check of the missing responses is performed. All variables have missing observations but the maximum number is 7 ( $x 44$ - neighbours), thus not raising any special problems (there is one observation with missing on all variables).

I performed then an exploratory factor analysis with ordinal categorical variables using Mplus7. I indicated a minimum of one and a maximum of three factors to be extracted. The result obtained suggested a two-factor solution. However, since one of the assumptions is that the solidarity actions are determined by one underlying value orientation, the first confirmatory factor analysis (WLSMV method $^{22}$ ) run considers a one factor solution (Table 4, Model 4).

\footnotetext{
20 The exact question wording is: '[For the past two years] Have you donated (offered without being asked directly or begged) money, food or goods to: ...'.

${ }^{21}$ For the questions coded $\times 45, x 46$ and $x 47$, the meaning of donation, written between parentheses, was eliminated.

22 The same estimator is used for all models employing categorical variables in this paper.
} 
Table 4.

\begin{tabular}{|l|c|}
\hline & Model 4 \\
\hline Fit indices & \\
\hline Chi-Square Test of Model Fit Value/df & 2.26 \\
\hline Chi-Square Value & 31.737 \\
\hline \multicolumn{1}{|c|}{ Pf } & 14 \\
\hline CFI & 0.004 \\
\hline TLI & 0.955 \\
\hline RMSEA & 0.932 \\
\hline WRMR23 & 0.080 \\
\hline Standardized factor loadings & 0.800 \\
\hline X41 (people in need) & \\
\hline X42 (people affected by natural disasters) & 0.864 \\
\hline X43 (sick people) & 0.674 \\
\hline X44 (neighbours) & 0.838 \\
\hline X45 (beggars) & 0.352 \\
\hline X46 (church) & 0.419 \\
\hline X47 (charities) & 0.398 \\
\hline
\end{tabular}

For this model the value of RMSEA is above the suggested cut off the value, TLI also does not pass the cut off while, some of the fit measures, pass the cut off criteria (CFI, WRMR). Considering Brown (2006), the loadings of $\mathrm{x} 44$ (neighbours) and $\mathrm{x} 46$ (Church) do not pass the cut off value of 0.4 and x45 (beggars) does not pass the cut off value of 0.5 (Hair et al. 2009). On balance the model should be rejected, therefore, the next step is to consider the EFA result and to run a model with two factors, testing the same time for discriminant validity (the existence of two separate constructs) as suggested by Hair et al. (2009). The results are presented in Table 5, Model 5, Figure 5. The fit values and loadings are acceptable (they pass the cut off value criteria), suggesting separate constructs, but the two factors have no clear theoretical meaning (especially S2). They do not represent, as assumed above, an institutional and a people oriented solidarity factor. Therefore, considering the results of both Model 4 and Model 5, it seems preferable to drop the items that load on S2 (neighbours, beggars and Church) and re-run a CFA only with the items that load on S1. The results are presented in Table 6, Model 6, Figure 6. Even though, again, most of the fit values and loadings are good (except RMSEA that does not pass the cut off value criteria - very

${ }^{23} \mathrm{Yu}(2002)$ suggests a cut-off value of 0.9 . 
likely due to the sample size) the significance of the factor can still be improved. Thus I choose to exclude the item $\times 47$ (charities), considering it addresses an institution not a category of people. When $x 47$ (charities) is excluded the factor has a simpler structure and clearer theoretical meaning (see Table 7, Model 7 for results).

Table 5.

\begin{tabular}{|l|c|}
\hline & Model 5 \\
\hline Fit indices & 1.17 \\
\hline Chi-Square Test of Model Fit Value/df & 15.227 \\
\hline Chi-Square Value & 13 \\
\hline $\mathrm{df}$ & 0.293 \\
\hline P-value & 0.994 \\
\hline CFI & 0.991 \\
\hline TLI & 0.029 \\
\hline RMSEA & 0.527 \\
\hline WRMR & \\
\hline
\end{tabular}

Figure 5.

Figure 6.

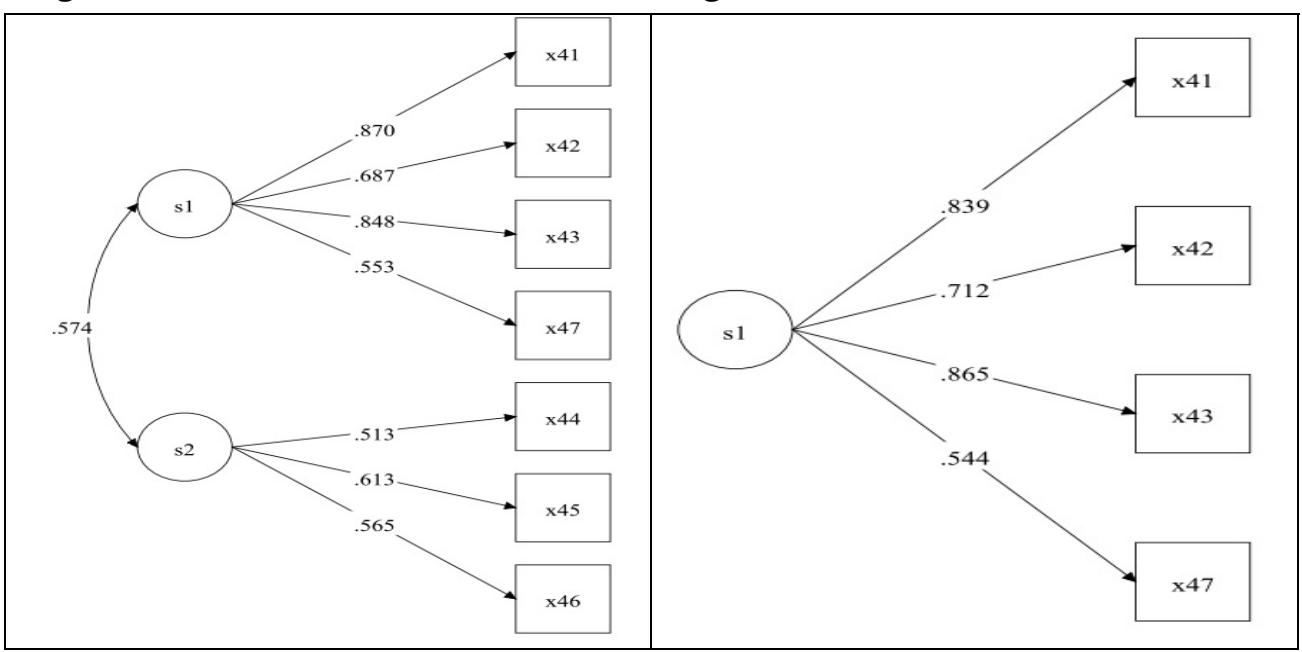

Table 6.

\begin{tabular}{|l|c|}
\hline & Model 6 \\
\hline Fit indices & 2.21 \\
\hline Chi-Square Test of Model Fit Value/df & 4.437 \\
\hline Chi-Square Value & 2 \\
\hline $\mathrm{df}$ & 0.108 \\
\hline P-value & 0.993 \\
\hline CFI & 0.979 \\
\hline TLI & 0.078 \\
\hline RMSEA & 0.400 \\
\hline WRMR & \\
\hline
\end{tabular}


Table 7.

\begin{tabular}{|l|c|}
\hline & Model 7 \\
\hline Fit indices & \\
\cline { 1 - 1 } Chi-Square Test of Model Fit Value/df & \multirow{2}{*}{ Just identified model } \\
\cline { 1 - 1 } Chi-Square Value, df, P-value & \\
\cline { 1 - 1 } CFI, TLI,. RMSEA, WRMR & \\
\hline Standardized factor loadings & 0.843 \\
\cline { 1 - 2 } X41 (people in need) & 0.674 \\
\hline X42 (people affected by natural disasters) & 0.886 \\
\hline X43 (sick people) & \\
\hline
\end{tabular}

\subsection{Nomological validity; external validation of the scales}

The first step in checking for nomological validity of the scale of solidarity acts is to verify its relation with the underlying factor(s) of the attitude scale of social solidarity. Thus the confirmatory factor analysis (with both continue and ordinal categorical variables) including all items (e154, e155, e156, e157, e158, e159, e160, e161, e162, x41, x42, x43) is run first. The results are presented in Table 8, Model 8 and Figure 7. On balance, the fit indices the fit indices in this model pass the suggested cut off criteria (except TLI). All the correlations between the underlying factor of social solidarity actions (s_new) and the three underlying factors of social solidarity attitudes (s_social, s_local and s_global) are rather small but positive and are going the same way. These results are suggesting that the three new items ( $x 41$, $x 42, x 43)$ fit the same general picture with the items measuring social solidarity attitudes and the this measurement scale is construct valid.

\section{Table 8.}

\begin{tabular}{|l|c|}
\hline \multicolumn{1}{|c|}{} & Model 8 \\
\hline Fit indices & 1.30 \\
\hline Chi-Square Test of Model Fit Value/df & 62.784 \\
\hline Chi-Square Value & 48 \\
\hline $\mathrm{df}$ & 0.074 \\
\hline P-value & 0.960 \\
\hline CFI & 0.945 \\
\hline TLI & 0.039 \\
\hline RMSEA & \\
\hline
\end{tabular}




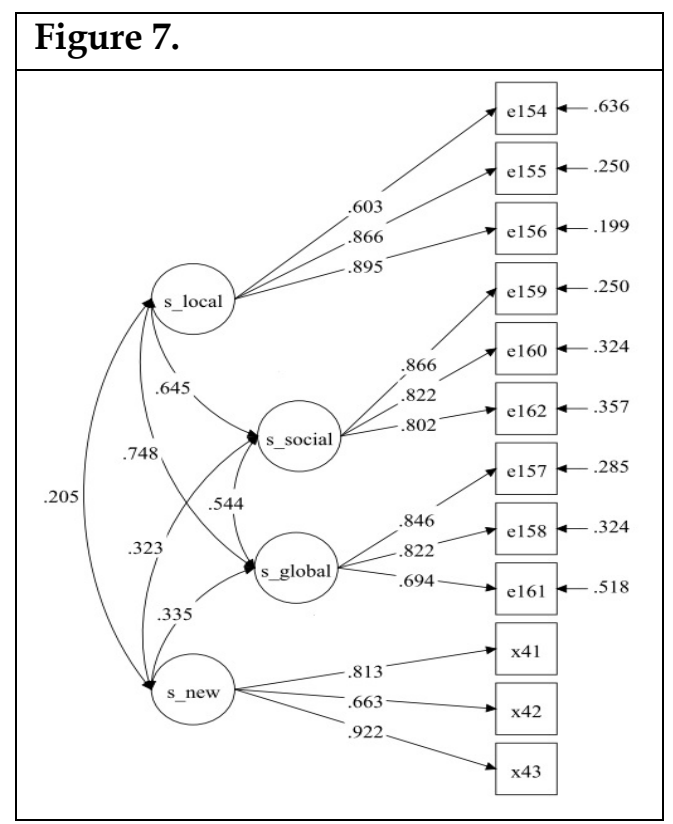

The second step is to verify both scales relation with external variables. That is a crucial step in assesing the construct validity of empirical measurements (Carmines and Zeller, 1979: 26). Thus I check if both scales (all four factors) correlate the same way with age, education and individualisation. The results are presented in Table 9 (the analysis is performed with SPSS 21).

Table 9.

\begin{tabular}{|l|c|r|r|r|}
\hline & Age & Individualism & Education & Income \\
\hline S_local & $.296^{* *}$ & -.019 & -.015 & -.048 \\
\hline S_social & $.403^{* *}$ & -.078 & -.009 & -.061 \\
\hline S_global & $.253^{* *}$ & -.095 & .005 & -.032 \\
\hline S_new & $.214^{* *}$ & -.030 & .018 & -.114 \\
\hline
\end{tabular}

Note: ${ }^{* *} \mathrm{p}<0.0125$

24 A value of 0.9 is the cut-off suggested by Muthen (1998-2004) for models with continuous and categorical outcomes.

${ }^{25}$ An accurate reading of the significance levels is: if the sample were representative, then the results obtained could be extended for the whole population with a probability of " $\mathrm{p}$ ". 
The results show positive, consistent correlations between age and each of the four factors. Also, the results are consistent for the relations with individualism (the direction of relation is negative as suggested by the theory) and income. The results are inconsistent for the relation with education. However, on balance, there are enough evidences suggesting that both, the modified scale of social solidarity attitudes and the proposed measurement scale of social solidarity acts are construct valid.

\section{Conclusion}

This paper was centred on construct validation. The main objective of the paper was to test for convergent validity (factor loadings and reliability) and nomological validity (Hair et al. 2009) of two sets of items aiming to measure social solidarity attitudes (Abela 2004) and acts. A scale of social solidarity acts was introduced and tested for both convergent and nomological validity on a convenience sample of 200 observations. At the same time a scale of social solidarity attitudes (Abela 2004; Kankaraš and Moors 2009) was tested for convergent validity on the Romanian sample of EVS 1999 and 2008 and for both convergent and nomological on the original data. The results show on one hand that the structure of the measurement model of socio-economic solidarity is different than the one suggested (see Abela 2004; Kankaraš and Moors 2009) in what concerns one of the latent variables (namely local solidarity). Thus, in a revised version, this scale should not contain the item capturing the concern for the living conditions of immediate family (e153). On the other hand the results show that both scales, the modified scale of social solidarity attitudes (where e153 is eliminated) and the proposed measurement scale of social solidarity acts (composed by the target categories: people in need-x41, people affected by natural disasters- $x 42$, and sick people-x43), are construct valid.

The analysis demands a cautious reading, given the characteristics of our original data (the sample). However, both the internal and validity checks provide sufficient evidence to consider that the empirical data support the proposed conceptual design. This can be further employed for analysing the latent orientations towards social solidarity in Romania. 


\section{Acknowledgement}

Working on this paper was supported by CNCS grants PN-II-RU-PD-2011-3-0132 and PN-II-ID-PCE-2011-3-0210.

\section{References}

Abela, Anthony M. 2004. Solidarity and religion in the European Union: A comparative sociological perspective. In The Value(s) of a Constitution for Europe. ed. Peter G. Xuereb, 71-101. Malta: European Documentation and Research Centre, University of Malta.

Arnsperger, Christian and Yanis Varoufakis. 2003. Toward a Theory of Solidarity. Erkenntnis 59 (2): 157-188.

Arts, Wil and John Gelissen. 2001. Welfare states, solidarity and justice principles: does the type really matter? Acta Sociologica 4 (4): 283-300.

De Beer, Paul and Ferry Koster. 2009. Sticking Together or Falling Apart? Solidarity in an Era of Individualization and Globalization. Amsterdam: Amsterdam University Press.

Brown, Timothy A. 2006. Confirmatory Factor Analysis for Applied Research. New York: The Guilford Press.

Carmines, Edward G. and Richard A. Zeller. 1979. Reliability and Validity Assessment. Beverly Hills: Sage Publications.

Byrne, Barbara. 2010. Structural Equation Modeling with Amos: basic concepts, applications, and programming. New York: Routledge.

Calhoun, Craig. 2007. Nations Matter Culture, History, and the Cosmopolitan Dream. New York: Roultledge.

Chen, Feinian, Patrick Curran, Kenneth Bollen, James Kirby, and Pamela Paxton (2008) An Empirical Evaluation of the Use of Fixed Cutoff Points in RMSEA Test Statistic in Structural Equation Models. Sociological Methods and Research 36 (4): 462-494.

Durkheim, Emile. 1964 [1895]. The Division of Labor in Society. New York: Free Press.

Ellison, Marion (ed.). 2011. Reinventing Social Solidarity Across Europe. Bristol: Policy Press.

Habermas, Jürgen. 1992. Citizenship and National Identity: Some Reflections on the Future of Europe. Praxis International 12 (1): 1-19.

Habermas, Jürgen. 1997. The European Nation-State: on the Past and Future of Sovereignty and Citizenship. In The Inclusion of the Other: Studies in Political Theory. eds. Ciaran Cronin and Pablo De Greiff. 106-127. Cambridge: MIT Press.

Hair, Joseph F. Jr., William C. Black, Barry J. Babin and Rolph E. Anderson. 2009. Multivariate Data Analysis. Upper Saddle River: Prentice Hall.

Hagenaars, Jacques, Loek Halman and Guy Moors. 2003. Exploring Europe's basic values map. in The Cultural Diversity of European Unity. Findings, Explanations 
and Reflections from the European Values Study. eds. Wil Arts, Jacques Hagenaars, and Loek Halman, 23-58. Leiden: Brill.

Inglehart, Ronald. 1997. Modernization and Post-Modernization. Cultural, Economic and Political Change in 43 Societies. Princeton: Princeton University Press.

Janmaat, Germen J. and Robert Braun. 2009. Diversity and Postmaterialism as Rival Perspectives in Accounting for Social Solidarity: Evidence from International Surveys. International Journal of Comparative Sociology 50 (1): 3968.

Kankaraš, Miloš and Guy Moors. 2009. Measurement Equivalence in Solidarity Attitudes in Europe Insights from a Multiple-Group Latent-Class Factor Approach. International Sociology 24 (4): 557-579.

Komter, Aafke. 2005. Social solidarity and the gift. Cambridge: Cambridge University Press.

Li-tze, Hu and Peter M. Bentler. 1999. Cutoff criteria for fit indexes in covariance structure analysis: Conventional criteria versus new alternatives. Structural Equation Modeling: A Multidisciplinary Journal 6 (1): 1-55.

Michalski, Krzysztof (ed.). 2006. What Holds Europe Together? Budapest: CEU Press.

Muthén, Linda K. and Bengt O. Muthén. 1998-2012. Mplus User's Guide. Seventh Edition. Los Angeles, CA: Muthén \& Muthén.

Muthén, Bengt O. 1998-2004. Mplus Technical Appendices. Los Angeles, CA: Muthén \& Muthén.

Radtke, Katrin. 2007. Transnational Solidarity in the Face of Humanitarian Crises: Trends in Voluntary Giving in Germany. Paper presented at the International Studies Association 48th Annual Convention, February 28 March 3, 2007, Chicago, USA, http://www.allacademic.com/ meta/p179186_index.html (accessed February 10, 2011).

Rokeach, Milton. 1973. The Nature of Human Values. New York: The Free Press.

Rusu, Horațiu. 2008. Identity and axiological profile: value identifications at Romanian young people. In The values of Romanians: 1993-2006. A sociological perspective, eds. Bogdan Voicu and Mălina Voicu, 231-262. Iași: Institutul European.

Stjernø, Steinar. 2004. Solidarity in Europe. The History of an Idea. Cambridge: Cambridge University Press.

Tönnies, Ferdinand. 1957 [1887]. Community and Society. East Lansing: Michigan State University Press.

Tufiș, Paula. 2008. Social-status and child rearing values. In The values of Romanians: 1993-2006. A sociological perspective. eds. Bogdan Voicu and Mălina Voicu, 193-231. Iași: Institutul European.

Yu, Ching-Yun. 2002. Evaluation of model fit indices for latent variable models with categorical and continuous outcomes. PhD diss., University of California, Los Angeles, http://www.statmodel.com/download/Yudissertation.pdf (accessed June 5, 2012) 